\title{
CHFR Promoter Methylation Indicates Poor Prognosis in Stage II Microsatellite Stable Colorectal Cancer
}

Citation for published version (APA):

Cleven, A. H. G., Derks, S., Draht, M. X. G., Smits, K. M., Melotte, V., Van Neste, L., Tournier, B., Jooste, V., Chapusot, C., Weijenberg, M. P., Herman, J. G., de Bruine, A. P., \& van Engeland, M. (2014). CHFR Promoter Methylation Indicates Poor Prognosis in Stage II Microsatellite Stable Colorectal Cancer. Clinical Cancer Research, 20(12), 3261-3271. https://doi.org/10.1158/1078-0432.CCR-12-3734

Document status and date:

Published: 15/06/2014

DOI:

10.1158/1078-0432.CCR-12-3734

Document Version:

Publisher's PDF, also known as Version of record

Document license:

Taverne

Please check the document version of this publication:

- A submitted manuscript is the version of the article upon submission and before peer-review. There can be important differences between the submitted version and the official published version of record.

People interested in the research are advised to contact the author for the final version of the publication, or visit the DOI to the publisher's website.

- The final author version and the galley proof are versions of the publication after peer review.

- The final published version features the final layout of the paper including the volume, issue and page numbers.

Link to publication

\footnotetext{
General rights Owners
rights.

- You may freely distribute the URL identifying the publication in the public portal. please follow below link for the End User Agreement:

www.umlib.nl/taverne-license

Take down policy

If you believe that this document breaches copyright please contact us at:

repository@maastrichtuniversity.nl

providing details and we will investigate your claim.
}

Copyright and moral rights for the publications made accessible in the public portal are retained by the authors and/or other copyright owners and it is a condition of accessing publications that users recognise and abide by the legal requirements associated with these

- Users may download and print one copy of any publication from the public portal for the purpose of private study or research.

- You may not further distribute the material or use it for any profit-making activity or commercial gain

If the publication is distributed under the terms of Article $25 \mathrm{fa}$ of the Dutch Copyright Act, indicated by the "Taverne" license above, 


\section{CHFR Promoter Methylation Indicates Poor Prognosis in Stage II Microsatellite Stable Colorectal Cancer}

Arjen H.G. Cleven ${ }^{1}$, Sarah Derks ${ }^{1}$, Muriel X.G. Draht ${ }^{1}$, Kim M. Smits ${ }^{1,2}$, Veerle Melotte ${ }^{1}$, Leander Van Neste ${ }^{1}$, Benjamin Tournier ${ }^{4}$, Valerie Jooste ${ }^{5}$, Caroline Chapusot ${ }^{4}$, Matty P. Weijenberg ${ }^{3}$, James G. Herman ${ }^{6}$, Adriaan P. de Bruïne ${ }^{1}$, and Manon van Engeland ${ }^{1}$

\section{Abstract}

Purpose: Data on the prognostic significance of promoter CpG island methylation in colorectal cancer (CRC) are conflicting, possibly due to associations between methylation and other factors affecting survival such as genetic alterations and use of adjuvant therapy. Here, we examine the prognostic impact of promoter methylation in patients with CRC treated with surgery alone in the context of microsatellite instability (MSI), BRAF and KRAS mutations.

Experimental Methods: One hundred and seventy-three CRCs were analyzed for promoter methylation of 19 tumor suppressor and DNA repair genes, the CpG island methylator phenotype (CIMP), MSI, the exon 15 V600E BRAF mutation and KRAS codon 12 and 13 mutations.

Results: Unsupervised hierarchical clustering based on methylation status of 19 genes revealed three subgroups: cluster 1 [CL1, 57\% (98/173) of CRCs], cluster 2 [CL2, 25\% (43/173) of CRCs], and cluster 3 [CL3, 18\% (32/173) of CRCs]. CL3 had the highest methylation index $(0.25,0.49$, and 0.69 , respectively, $P=<0.01)$ and was strongly associated with CIMP $(P<0.01)$. Subgroup analysis for tumor stage, MSI, and $B R A F$ status showed no statistically significant differences in survival between CL1, CL2, and CL3 nor between CIMP and non-CIMP CRCs. Analyzing genes separately revealed that CHFR promoter methylation was associated with a poor prognosis in stage II, microsatellite stability (MSS), BRAF wild-type (WT) CRCs: multivariate Cox proportional HR $=3.89$ [95\% confidence interval (CI), 1.58-9.60, $P<0.01 ; n=66$ ] and $\mathrm{HR}=2.11(95 \% \mathrm{CI}, 0.95-4.69, P=0.068, n=136)$ in a second independent population-based study.

Conclusions: CHFR promoter CPG island methylation, which is associated with MSI, also occurs frequently in MSS CRCs and is a promising prognostic marker in stage II, MSS, BRAF WT CRCs. Clin Cancer Res; 20(12); 3261-71. (C2014 AACR.

\section{Introduction}

Accurate staging of colorectal cancer (CRC) is essential for optimal disease management. Although patients with the same stage can demonstrate considerable variation in outcome, the tumor-node-metastasis (TNM) staging system remains the gold standard for predicting prognosis and guiding clinical management of CRC.

Authors' Affiliations: Departments of ${ }^{1}$ Pathology, ${ }^{2}$ Radiation Oncology (MAASTRO) and ${ }^{3}$ Epidemiology, GROW-School for Oncology and Developmental Biology, Maastricht University Medical Center, Maastricht, the Netherlands; ${ }^{4}$ Service de Pathologie; ${ }^{5}$ Registre des cancers digestifs, Université de Bourgogne, Centre Hospitalier Universitaire de Dijon, Dijon, France; and ${ }^{6}$ The Sidney Kimmel Comprehensive Cancer Center at the Johns Hopkins University School of Medicine, Baltimore, Maryland

Note: Supplementary data for this article are available at Clinical Cancer Research Online (http://clincancerres.aacrjournals.org/).

Corresponding Author: Manon van Engeland, Department of Pathology, GROW-School for Oncology and Developmental Biology, Maastricht University Medical Center, PO BOX 616, 6200 MD Maastricht, the Netherlands. Phone: 31-43-3874622; Fax: 31-43-3876613; E-mail:

manon.van.engeland@mumc.nl

doi: 10.1158/1078-0432.CCR-12-3734

(c)2014 American Association for Cancer Research.
Adjuvant chemotherapy is recommended for all stage III CRC patients. In Europe, the majority of stage II CRC patients undergo surgery alone, despite the recognition that a subgroup with a poor prognosis would probably benefit from adjuvant chemotherapy. Molecular classification of CRC might aid in selecting patients with CRC who could benefit from adjuvant therapy.

CRC is characterized by (epi)genetic alterations of genes controlling the hallmarks of cancer (1-4). Frequently observed alterations affecting these pathways include chromosomal instability (CIN), microsatellite instability (MSI), coding sequence mutations in $A P C$, TP53, KRAS, and PIK3CA $(3,4)$ and promoter CpG island hypermethylation (5). A distinct subset of CRCs, characterized a greater degree of promoter CpG island methylation, is associated with proximal location, poor differentiation, MSI, and BRAF mutations $(6-11)$ and is referred to as the $\mathrm{CpG}$ island methylator phenotype (CIMP; refs. 10, 12).

CIMP has previously been associated with CRC prognosis. However, published reports are inconsistent, perhaps due to confounding factors such as MSI, BRAF, and KRAS mutations, variations in use of adjuvant chemotherapy 


\section{Translational Relevance}

Here, we present CHFR promoter CpG island methylation as a prognostic biomarker for stage II, microsatellite stability, BRAF wild-type CRCs in two independent population series. This finding could aid in the identification of high-risk stage II colorectal cancer (CRC) patients. The use of adjuvant chemotherapy for stage II colon cancer is still controversial because parameters to accurately identify stage II CRC patients at risk for recurrence are lacking. Currently, these patients are being identified by clinicopathological parameters such as the T stage, number of lymph nodes examined, tumor differentiation, tumor perforation, vascular, lymphatic and perineural invasion, and tumor budding. However, some of these parameters are subject to interobserver variability and lack reproducible scoring systems. CHFR methylation can facilitate better selection of high-risk stage II CRC patients for adjuvant therapy.

(13-16), and methodologic differences, such as different CIMP definitions $(12,17)$.

The aim of this study was to explore the role of CIMP and frequently methylated promoter $\mathrm{CpG}$ islands on prognosis of CRC, eliminating the influence of genetic alterations and adjuvant chemotherapy.

\section{Material and Methods \\ Study population}

For the study population, we used CRC material from patients that were entered in two clinical studies in the Netherlands between 1979 and 1981. One trial was designed to compare patient survival after treatment for CRC by conventional surgery $(n=119)$ or the no-touch isolation technique ( $n=117$; ref. 18$)$ The two treatment groups were comparable with regard to patient characteristics. The survival between these groups was not statistically different between both groups. One hundred and fourteen cases with tumor material were available for analysis. From a second clinical study, designed to compare outcome in rectal cancer patients with and without preoperative radiotherapy (19), only the patients in the no-preoperative radiotherapy arm $(n=114)$ were included. From this group, tumor material from 59 rectum cases was available. At the time these studies were conducted, adjuvant chemotherapy was not yet standard practice. None of the patients in the study population received chemotherapy. Tumor stage was defined according to the UICC-TNM staging system and American Joint Committee on Cancer classifications, Cancer Staging Sixth Edition. For both studies, follow-up took place every 3 months during the first 3 years and every 6 months between 3 years and 5 years after initial diagnosis and surgery. Standard protocols were followed, with routine blood counts and chemistry studies (including carcinoembryonic antigen levels) at each visit and liver ultrasound, chest X-ray, and colonoscopy annually, to evaluate recurrence of disease and disease-related death. After 5 years of follow-up, only time and cause of death were registered. Follow-up was complete for all patients. Failure was defined as death due to recurrent disease, excluding postoperative mortality within 30 days, and non-disease-related death. For molecular analyses, tumor tissues from $173(114+59)$ tissue samples of patients with primary CRC were available.

\section{Independent validation population of CRCs}

A second, independent population of 734 CRC cases, derived from the prospective Netherlands Cohort Study on diet and cancer which started in 1986 with the enrolment of 120,852 healthy individuals between 55 years and 69 years old from 204 municipalities throughout the Netherlands, was used to validate survival data. From 1989 to 1994, 925 incident CRC cases (ICD-O: 153.0-154.1) were identified by computerized linkage with the Netherlands Cancer Registry and PALGA, a nationwide network and registry of histopathology and cytopathology (20). Information on tumor localization, tumor staging, differentiation grade, and incidence date was available through the Netherlands Cancer Registry. Vital status until May 2005 was retrieved from the Central Bureau of Genealogy and the municipal population registries and could be obtained for all cases Causes of death were retrieved through linkage with Statistics Netherlands. Paraffin-embedded tumor tissue was collected from 54 pathology registries; tissue blocks for 734 (90\%) of the CRC cases contained sufficient DNA for analyses. Details of this cohort have been described

\begin{tabular}{|c|c|c|c|}
\hline & $\begin{array}{c}\text { Study } \\
\text { population } \\
(n=173)\end{array}$ & $\begin{array}{l}\text { Validation } \\
\text { population } \\
(n=569)\end{array}$ & $\boldsymbol{P}$ \\
\hline \multicolumn{4}{|l|}{ Age } \\
\hline Mean age (SD) & $67.8(11.8)$ & $63.1(4.1)$ & $<0.001$ \\
\hline \multicolumn{4}{|l|}{ Gender } \\
\hline Male & $82(47 \%)$ & 303 (53.3) & 0.177 \\
\hline Female & $91(53 \%)$ & 266 (46.7) & \\
\hline \multicolumn{4}{|l|}{ Tumor location } \\
\hline Right-sided colon & $62(36 \%)$ & $210(37.2)$ & $<0.001$ \\
\hline Left-sided colon & 52 (30\%) & 253 (44.9) & \\
\hline Rectum & $59(34 \%)$ & $101(17.9)$ & \\
\hline \multicolumn{4}{|l|}{ CRC stage } \\
\hline 1 & $4(2 \%)$ & $172(30.9)$ & $<0.001$ \\
\hline ॥ & 100 (58\%) & $201(36.2)$ & \\
\hline III & $50(29 \%)$ & $127(22.8)$ & \\
\hline IV & 19 (11\%) & $56(10.1)$ & \\
\hline Event frequency ${ }^{a}$ & $64(38 \%)$ & $210(37.1)$ & 0.774 \\
\hline Median follow-up time & $4.8 \mathrm{y}$ & $8.9 y$ & $<0.001$ \\
\hline
\end{tabular}




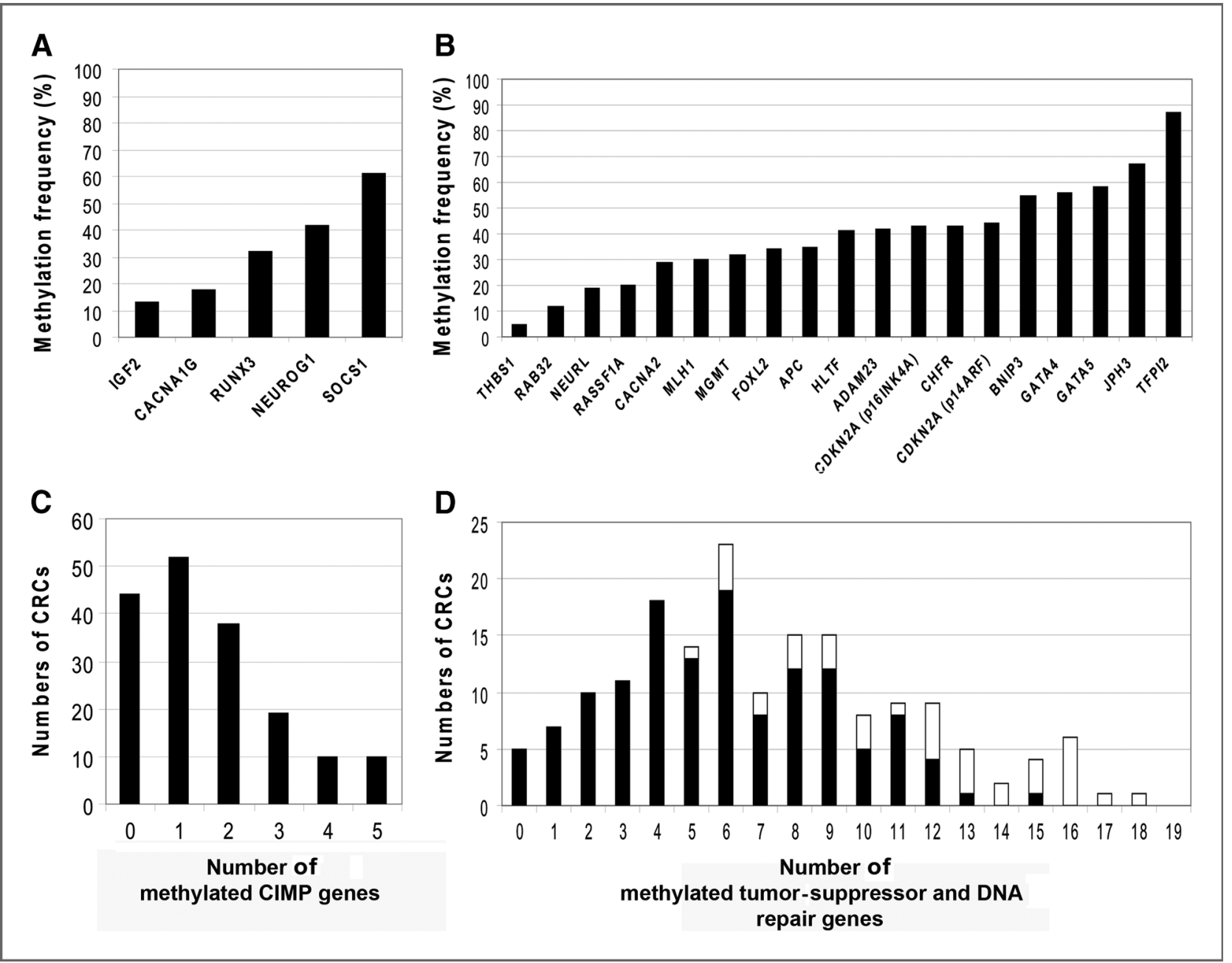

Figure 1. A, methylation frequencies of the five CIMP genes in the study population (black bars indicate percentages). B, methylation frequencies of 19 additional tumor suppressor- and DNA repair genes in the study population (black bars indicate percentages). C, distribution of CRC cases according to the number of methylated CIMP genes (black bars indicate number of cases). D, distribution of CRC cases according to the number of methylated tumor suppressor and DNA repair genes (black bars indicate number of cases $\mathrm{CIMP}^{-}$, white bars indicate number of cases $\mathrm{CIMP}^{+}$).

previously (21). For 714 cases, therapy data were available. Of these 714 cases, 145 patients received chemo-or radiotherapy, leaving 569 cases not treated with additional therapies that will be used for analyses.

Clinical pathologic characteristics are provided for both populations (Table 1). In the validation study, younger patients $(P<0.001)$, more left-sided tumors $(P<0.001)$ and stage I tumors $(P<0.001)$, were diagnosed and the median follow-up time was longer in the validation population: 8.9 years compared with 4.8 years $(P<0.001)$. However, event frequencies were comparable between both studies, making the validation population suitable for validation of prognostic markers.

\section{Promoter CpG island methylation, MSI and BRAF and KRAS analysis}

Genomic DNA was extracted from CRC tissues using PureGene Genomic DNA Isolation Kit (Gentra Systems) according to the manufacturer's protocol.
Promoter CpG island methylation of genes reported to be methylated in CRC $(2,5,22,23)$ : mutL homolog1, colon cancer, nonpolyposis type 2 (Escherichia coli; MLH1), cyclin-dependent kinase inhibitor 2A (CDKN2A; p16INK4 and p14ARF), O-6-methylguanine-DNA methyltransferase (MGMT), Ras association (RalGDS/AF-6) domain family member 1 (RASSF1A), adenomatous polyposis coli (APC), helicase-like transcription factor (HLTF), GATA-binding protein 4 (GATA4), GATA-binding protein 5 (GATA5), checkpoint with forkhead and ring finger domains (CHFR), ADAM metallopeptidase domain 23 (ADAM23), Rab32, member RAS oncogene family (RAB32), junctophilin (JPH3), forkhead box L2 (FOXL2), BCL2-adenovirus E1B 19kDA interacting protein 3 (BNIP3), neutralized homolog (Drosophila; NEURL), calcium channel, voltage dependent, $\alpha 2-$ delta subunit 1 (CACNA2), thrombospondin 1 (THBS1), tissue factor pathway inhibitor 2 (TFPI2), and the CIMP genes calcium channel, voltage-dependent, T type, $\alpha-1 G$ subunit (CACNA1G), insulin-like growth factor-II (somatomedin 


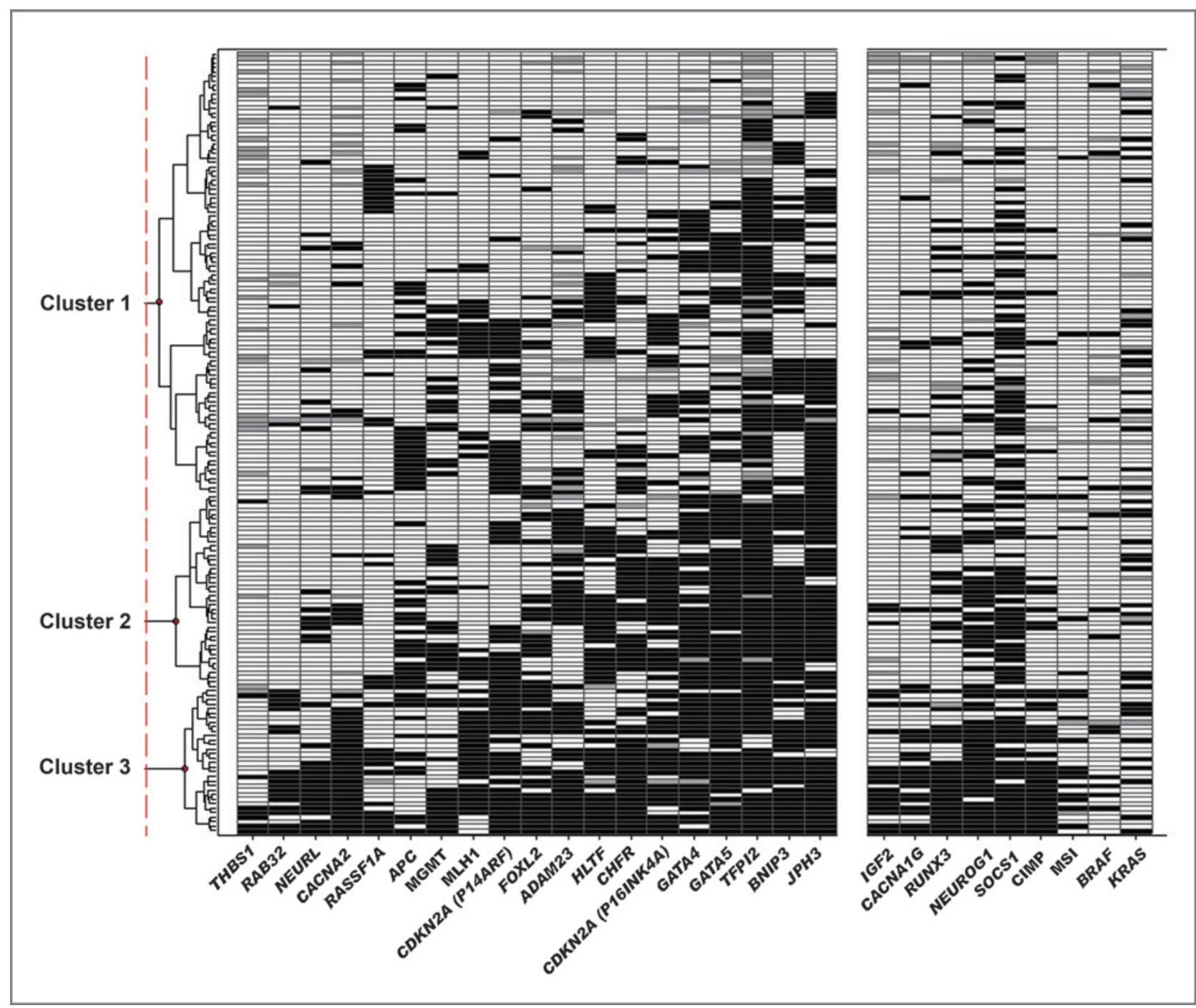

Figure 2. CRC clusters CL1 (57\%), CL2 (25\%), CL3 (18\%) obtained by unsupervised hierarchical clustering of promoter CpG island methylation of $M L H 1$, CDKN2A (p16INK4A), CDKN2A (p14ARF), MGMT, RASSF1A, APC, HLTF, GATA4, GATA5, CHFR, ADAM23, RAB32, JPH3, FOXL2, BNIP3, NEURL, CACNA2, THBS1, TFPI2. A black box indicates a methylated gene, a white box indicates an unmethylated gene, and a gray box indicates a failed PCR. After clustering, identification of patients was done for individual CIMP markers (CACNA1G, IGF2, NEUROG1, RUNX3, and SOCS1), CIMP, MSI, BRAF-, and KRAS mutations as visualized. Black box indicates positive, white box indicates negative, and gray box indicates missing value.

A, IGF-II), neurogenin 1 (NEUROG1), runt-related transcription factor 3 (RUNX3), and suppressor of cytokine signaling 1 (SOCS1) were determined using sodium bisulfite modification of genomic DNA (EZ DNA Methylation Kit, ZYMO research Co.). To facilitate methylation-specific PCR (MSP) analysis on DNA retrieved from formalinfixed, paraffin-embedded tissue, nested MSP was performed as described elsewhere $(24,25)$. Primers and PCR conditions are provided in Supplementary Table S1.

MSI was determined by a pentaplex PCR, using the mononucleotide MSI markers BAT-26, BAT-25, NR-21, NR-22, and NR-24, as previously described (26). MSI was defined positive when three or more of five markers (BAT-26, BAT-25, NR-21, NR-22, and NR-24) showed allelic size variants.

The common V600E BRAF mutation in exon 15 was analyzed by semi-nested PCR and subsequent restriction fragment length polymorphism (RFLP) analysis, KRAS mutations were analyzed as described previously $(27,28)$.

\section{Data analysis}

A consensus marker panel to analyze CIMP in CRC has not been established yet (12). We analyzed CIMP using the marker panel proposed by Weisenberger and colleagues (11). CRCs were defined as CIMP when $\geq 3$ of 5 analyzed markers (CACNA1G, IGF2, NEUROG1, RUNX3, and SOCS1) were methylated. Unsupervised clustering (Spotfire DecisionSite for Functional Genomics), based on the similarity of methylation of $19 \mathrm{CpG}$ islands that have been reported to be methylated in CRC (CIMP genes excluded), was performed by using half-square Euclidian distance (Wards method linkage rule; refs. 29, 30). Methylation index $(\mathrm{MI}=$ number of methylated promoter $\mathrm{CpG}$ islands divided 
Table 2. Correlations between CIMP, CL1, CL2, and CL3 and MSI and BRAF mutation in the study population

MSI

$12 / 19(63 \%)$

$3 / 19(16 \%)$

$4 / 19(21 \%)$

$12 / 19(63 \%)$
MSS

$26 / 145(18 \%)$

$<0.01$

$\mathrm{CL} 1$

CL2

CL3
$94 / 150(63 \%)$

$38 / 150(25 \%)$

$18 / 150$ (12\%)

$<0.01$
BRAF M

7/14 (50\%)

$5 / 14(36 \%)$

$3 / 14(21 \%)$

$6 / 14(43 \%)$
BRAF WT

32/143 (22\%)

$<0.05$

$83 / 147(57 \%)$

$39 / 147$ (27\%)

25/147 (17\%)

0.06
CIMP

6/39 (15\%)

$8 / 39(21 \%)$

25/39 (64\%)

$<0.01$

NOTE: CIMP using the markers of Weisenberger et al. (11). CL1, CL2, and CL3, groups of CRCs identified by unsupervised hierarchical clustering based on methylation patterns of 19 tumor suppressor and DNA repair genes. The Pearson $\chi^{2}$ test was used. The Fisher exact test was used if there were less than five objects in any category.

Abbreviation: $\mathrm{M}$, mutant.

by number of promoter CpG islands successfully analyzed) was calculated using the promoter CpG islands of 19 tumor suppressor- and DNA repair genes as well as the CIMP panel. To assess normality for the distribution of CRC cases according to the number of methylated CIMP genes and number of methylated tumor suppressor genes, we calculated the sample skewness divided by the standard error of skewness. Normality was rejected if the ratio was less than -2 or more than +2 . In addition, quantile-quantile plots were generated to compare the shapes of the distributions. Differences between methylation, clinicopathological, and molecular characteristics were determined by the Pearson $\chi^{2}$ test and the Fisher exact test in cases with $<5$ subjects in any category. Kaplan-Meier curves were used to evaluate the relationship between promoter $\mathrm{CpG}$ island methylation and patient survival in the overall population and stratified for tumor stage, MSI, and BRAF mutation status. For graphical reasons, to increase comparability of the curves in the two populations, Kaplan-Meier curves were cutoff at 10 years of follow-up for the validation population. For Cox proportional hazard analyses, maximal follow-up periods were used. Statistical differences between groups were assessed by use of the log-rank test. The endpoint for analyses was cancer-specific survival starting from the day of surgery to the time of death due to CRC. Independent variables predicting survival were evaluated in a multivariate model using Cox Regression analyses. The Cox regression model including CIMP, CL1, CL2, CL3, CHFR promoter CpG island methylation, age, gender, tumor location, differentiation grade, and TNM stage was used to assess the prognostic influence of these variables. All $P$ values (two sided) $<0.05$ were considered statistically significant. SPSS 15.0 and Stata 11.2 were used for data analyses.

\section{Results}

\section{(Epi)genetic characterization of CRCs}

MSI, BRAF, and KRAS mutations were detected in $11 \%$ (19/169), 9\% (14/161), and 26\% (41/157) of CRCs of the

Table 3. Cox proportional hazard models for MSS, BRAF WT, stage II CRCs

\begin{tabular}{|c|c|c|c|c|c|c|}
\hline & \multicolumn{3}{|c|}{ Study population $(n=66)$} & \multicolumn{3}{|c|}{ Validation population $(n=136)$} \\
\hline & $n$ & $\begin{array}{l}\text { CRC mortality, } \\
\text { HR (95\% Cl) }\end{array}$ & $P$ & $n$ & $\begin{array}{l}\text { CRC mortality, } \\
\text { HR (95\% Cl) }\end{array}$ & $\boldsymbol{P}$ \\
\hline CHFR $M^{a}$ & 28 & $3.89(1.58-9.60)$ & $<0.01$ & 44 & $2.11(0.95-4.69)$ & 0.06 \\
\hline Age, y & & $1.02(0.97-1.07)$ & 0.41 & & $1.06(0.95-1.17)$ & 0.31 \\
\hline Gender (female ${ }^{b}$ ) & 34 & $0.53(0.23-1.27)$ & 0.16 & 60 & $1.59(0.71-3.58)$ & 0.26 \\
\hline \multicolumn{7}{|l|}{ Tumor location } \\
\hline Left-sided colon ${ }^{c}$ & 24 & $0.52(0.20-1.38)$ & 0.19 & 54 & $1.08(0.43-2.71)$ & 0.87 \\
\hline Rectum $^{\mathrm{c}}$ & 25 & $0.29(0.09-0.93)$ & 0.04 & 11 & $3.23(0.90-11.66)$ & 0.07 \\
\hline Differentiation grade poor $^{d}$ & 26 & $1.52(0.69-3.36)$ & 0.30 & 10 & $0.92(0.08-17.38)$ & 0.95 \\
\hline
\end{tabular}

Abbreviations: $\mathrm{H}$, hazard ratio=relative risk; $\mathrm{M}$, methylated.

${ }^{a}$ Reference group $=$ CHFR unmethylated cases.

${ }^{\mathrm{b}}$ Reference group $=$ male.

${ }^{\mathrm{c}}$ Reference group $=$ right-sided colon.

${ }^{\mathrm{d}}$ Reference group $=$ well $/$ moderate . 


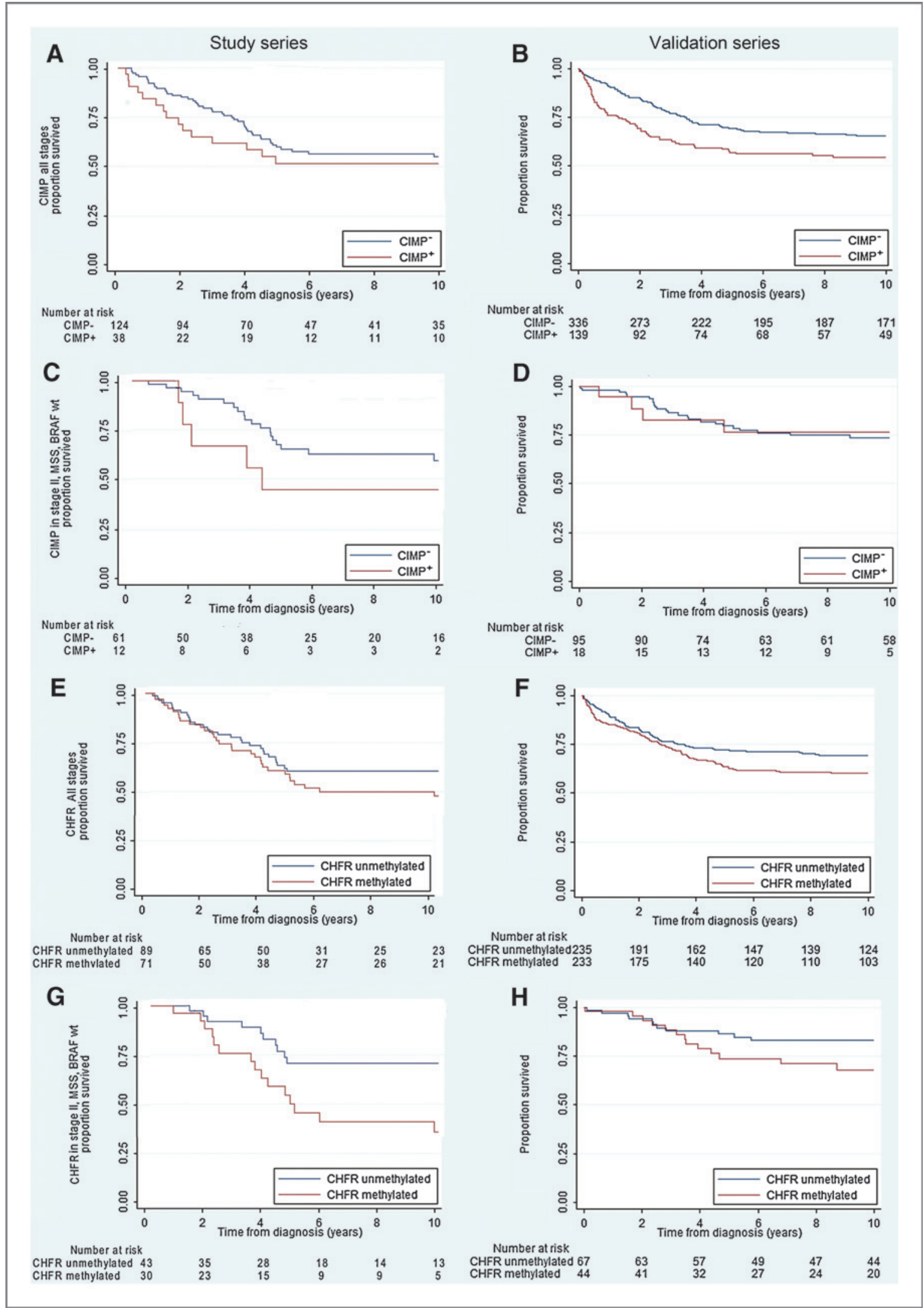


study population, respectively (Supplementary Table S2), which is in accordance with previously reported frequencies $(3,4,31)$.

The methylation frequency for CIMP genes ranged from $13 \%$ to $61 \%$ : IGF2 [13\% (20/154)], CACNA1G [18\% (30/170)], RUNX3 [32\% (52/163)], NEUROG1 [42\% (70/165)], and SOCS1 [61\% (103/170); Fig. 1A]. Twenty-three percent $(39 / 168)$ of CRCs were classified as CIMP (Supplementary Table S3). This is consistent with previous publications with reported frequencies of CIMP between $18 \%$ to $25 \%(11,32,33)$.The distribution of the number of CIMP markers methylated for each tumor resembles a normal distribution (Fig. 1C; sample skewness/standard error of skewness $=0.187$; which was confirmed by a quantile-quantile plot analysis, data not shown).

We sought to more broadly examine the methylation of CpG islands in CRC to determine whether the five genes used to define CIMP optimally separated phenotypic differences in colorectal tumors. The frequency of promoter CpG island methylation in 19 additional tumor suppressor genes ranged from 5\% (THBS1) to 87\% (TFPI2); (Fig. $1 \mathrm{~B}$ and Supplementary Table S2), of which many correlated strongly. We compared the distribution of tumors according to the methylation status of the 19 additional genes (Fig. 1D). This resembles a normal distribution (sample skewness/standard error of skewness $=0.185$; confirmed by quantile-quantile plot analysis, data not shown) and reveals that CRCs with a high number of methylated genes are predominantly characterized by CIMP (white bars). This suggests that the Weisenberger CIMP markers are sensitive but not completely specific in identifying CRCs with a high frequency of promoter CpG island methylation.

We assessed whether subgroups of CRCs could be identified using methylation patterns of the 19 non-CIMP genes. Unsupervised hierarchical cluster analysis identified three clusters of CRCs, CL1 [57\% (98/173)], CL2 [25\% (43/173)], and CL3 [18\% (32/173); Fig. 2 and Supplementary Table S3]. CL3 showed the highest number of methylated genes (MI; mean $\mathrm{MI}, \mathrm{CL} 1=0.25 ; \mathrm{CL} 2=0.49 ; \mathrm{CL} 3=0.69 ; P=<0.001)$.

\section{Associations between genetic, epigenetic, and clinicopathological characteristics}

CIMP was highly associated with promoter CpG island methylation of 16 of 19 additional genes. Furthermore, CRCs grouped in CL3 were most often classified as CIMP $(P<0.01$; Fig. 2; Table 2). CIMP was associated with MSI, BRAF mutations, and CL3 $(P<0.01, P=0.05$, and $P<0.01$, respectively; Table 2$)$. Sixty-nine percent $(26 / 38)$ of CIMP CRCs and 60\% (18/30) of CL3 CRCs are microsatellite stability (MSS; Table 2). Mutations in KRAS were neither associated with CIMP nor with the identified clusters (data not shown).

As expected, CIMP and MSI were associated with rightsided tumor location, as were CL3 CRCs $(P=<0.01, P=$ $<0.01$, and $P=<0.01$, respectively; Supplementary Tables S2 and S3). We did not observe previously reported association between sex, age, and CIMP or with our newly defined CL3 tumors.

The aim of this study was to evaluate the prognostic influence of promoter $\mathrm{CpG}$ island methylation using CIMP and to extend this analysis to include 19 additional tumorsuppressor and DNA repair genes. As tumor stage, MSI, $B R A F$, and KRAS mutations have in some reports influenced survival, we analyzed whether these alterations were of prognostic significance in the study population. As expected, disease outcome was significantly influenced by tumor stage, with stage I having an improved overall survival compared with other tumor stages $(P<0.01$, data not shown). We also observed that wild-type (WT) BRAF tumors showed an improved overall survival compared with BRAF-mutated tumors $(P=0.04$, data not shown). MSI was also associated with improved overall survival as compared with MSS within CRC stage II, although this association is not statistically significant $(P=0.07$, data not shown). KRAS mutations were of no prognostic value, neither in the overall population nor in the separate stages (data not shown). Therefore, survival analyses were also performed for subgroups based on stage, MSI status, and BRAF mutation status.

No statistically significant survival differences between CIMP and non-CIMP CRCs were observed in the overall study population $(P=0.381 ;$ Fig. $3 A)$, or when specifically examining stage II $(P=0.16$; Fig. $3 C)$ or stage III (data not shown) MSS, BRAF WT CRCs. The same was observed for CL1, CL2, and CL3 CRCs (data not shown). Examining the 569 patients of the validation population not treated with adjuvant therapy showed a statistically significant association between CIMP and prognosis in the overall population $(P=0.004$; Fig. 3B $)$ but neither in stage II MSS BRAF WT CRCs $(P=0.955$; Fig. 3D) nor the stage III MSS BRAF WT CRCs (data not shown). Extending these analyses using the full follow-up period of the validation population, did not alter these conclusions $(P=0.0087$ for the overall and $P=$ 0.867 for stage II, MSS BRAFWT cases; data not shown). We next sought to determine whether one possible explanation for additional variation in previous studies was that specific CpG island methylation, underlying any prognostic importance, was imperfectly associated with CIMP. When analyzing all 19 (or 24 if including CIMP) genes in a univariate analysis, only APC and CHFR methylation, although the latter was positively associated with MSI $(P=0.02)$ and

Figure 3. Survival curves for CIMP-positive and CIMP-negative $\mathrm{CRCs}$ for the overall study population $(\mathrm{A}, P=0.381)$ and validation population (B, $P=0.004)$. Survival curves for stage II, MSS, and BRAFWT CRCs for the study population $\mathrm{CIMP}^{+}(n=12)$ and $\mathrm{CIMP}^{-}(n=61), P=0.16(\mathrm{C})$ and of the validation population $\mathrm{CIMP}^{+}(n=18)$ and $\mathrm{CIMP}^{-}(n=95), P=0.95$ (D). Survival curves for the overall population of $C H F R$ unmethylated $(n=89)$ versus $C H F R$ methylated $(n=71)$, $P=0.26$ (E); and for the validation population CHFR unmethylated $(n=235)$ versus CHFR methylated $(n=233), P=0.06$ (F). Survival curves for stage II, MSS, and BRAF WT tumors for CHFR unmethylated $(n=43)$ and CHFR methylated $(n=30)$ CRCs, $P=0.02$ (G); and for the validation population CHFR unmethylated $(n=67)$ and CHFR methylated $(n=44)$ CRCs, $P=0.10(\mathrm{H})$. 
CIMP $(P<0.01$; Supplementary Table S4), were associated with a worse prognosis in stage II MSS, BRAF WT CRCs $(\mathrm{HR}=2.63 ; 95 \%$ confidence interval $(\mathrm{CI}), 1.21-5.68, P=$ 0.01 and $\mathrm{HR}=2.59 ;(95 \% \mathrm{CI}, 1.16-5.76, P=0.02$, respectively; Fig. 3G; Supplementary Table S5). For stage III MSS BRAF WT CRCs, associations with worse prognosis were found for RASSF1A, THBS1, and CACNA1G (HR = 3.89; 95\% CI, $1.23-12.3, P=0.02 ; \mathrm{HR}=26.5 ; 95 \% \mathrm{CI}$, $1.66-423, P=0.02$ and $\mathrm{HR}=5.62 ; 95 \% \mathrm{CI}, 1.49-21.3, P=$ 0.01; Supplementary Table S5). These effects were not observed in the overall study population (Supplementary Table S5). Because of the small numbers of cases, the number of comparisons examined to find significance and the broad confidence intervals raised concerns, we decided to validate these results in an independent validation population. Cox proportional hazard analysis confirmed an association with prognosis only for CHFR methylation in stage II, MSS, BRAF WT CRCs (HR = 2.11; 95\% CI, 0.954.69, $P=0.068$; Fig. 3F and $\mathrm{H}$; Table 3). Again, extending the Kaplan Meier (KM) analyses to maximal follow-up did not alter these conclusions (data not shown). The Cox regression multivariate model within the study population of MSS, BRAF WT, stage II CRCs shows that CHFR methylation was associated with a poor prognosis ( $\mathrm{HR}=3.89$; 95\% CI, 1.58-9.60, $P=<0.01$ ) and was, in this study, a better predictor of survival than differentiation grade $(\mathrm{HR}=$ 1.52; 95\% CI, 0.69-3.36, $P=0.30$; Table 3).

\section{Discussion}

Data on the prognostic significance of promoter $\mathrm{CpG}$ island methylation, and CIMP in particular, are conflicting in CRC (13-16). These inconsistencies might be caused by factors affecting the course of the disease, such as genetic alterations, adjuvant therapy, and differences in methodologic study approaches. Here, we analyzed the prognostic value of promoter CpG island methylation in CRCs from patients not treated with (neo)adjuvant therapy taking into account the confounding role of clinicopathological and genetic (MSI and BRAF) characteristics. Previously reported associations between CIMP and proximal tumor location, MSI, and BRAF mutations' $(10,11,16)$ as well as the identification of three subgroups of CRCs $(9,34-36)$ based on promoter methylation profiles could be confirmed. In addition, the prognostic role of tumor stage, MSI, and BRAF $(37,38)$ could be confirmed in the study and the validation series.

We could not observe a statistically significant association of CIMP or CL3 with prognosis, neither overall nor when analyzed for stage or microsatellite status. These conclusions are valid for the subgroups of CRC defined by analyzing CIMP with the markers proposed by Weisenberger and colleagues (11) and also for unsupervised clustering of the methylation data for the 19 CpG islands that we added to the analysis. Because also other CIMP definitions have been used, caution with generalizing these conclusions is warranted (17). The statistically significant prognostic effect of CIMP in the validation series indicates that the prognostic role of CIMP in CRC is still unclear and that large, independent studies are needed to answer this question. In addition, until the underlying biologic cause for CIMP is being identified, an accurate definition remains hard to establish. Our evidence for imperfect correlation of highly methylated tumors using the independent 19 genes with CIMP illustrates this.

However, our data confirm the concept that based on CpG island methylation, three subgroups of CRC can be identified, independently of the specific markers used. The subgroup characterized by extensive promoter CpG island methylation is strongly, although not perfectly, associated with CIMP and its reported clinicopathological characteristics.

Performing subgroup analysis for established confounders including age, gender, tumor location, differentiation grade, TNM stage, MSI, and BRAF mutation status, promoter methylation of only 1 of 24 genes, namely CHFR, showed a strong association with poor prognosis in stage II MSS CRCs in the study population ( $\mathrm{HR}=3.89$; $95 \% \mathrm{CI}, 1.58-9.60, P<0.01)$ and the validation series $(\mathrm{HR}=2.11 ; 95 \% \mathrm{CI}, 0.95-4.69, P=0.068)$. Because of the assumption that many biomarker data are false, and the fact that we studied many variables without adjustment for multiple testing, these data should be considered exploratory and hypothesis generating. Validation of the effect of CHFR promoter CpG island methylation in an independent prospective cohort study as well as a small pilot study recently published by an independent team pointing into the same direction (39), underscores the potential of CHFR promoter CpG island methylation as a prognostic marker in CRC. Additional supporting evidence for the effect of CHFR methylation comes from a collection of CRCs collected by the Ferdinand Cabanne Biological Resources Centre from Dijon, France $(40,41)$. In this study, we observed that CHFR methylation, although not statistically significant, was associated with a worse overall survival (data not shown). Independent validation of our results in large series of CRCs will provide the best evidence for the clinical value of CHFR methylation as a marker for prognosis in stage II, MSS, BRAF WT CRCs. However, currently no studies that analyzed CHFR methylation at the same genomic location (42), in a comparable subgroup of CRCs, using the same endpoints are available, preventing the use of meta-analysis for combined analyses of these data.

A dominant effect of MSI over DNA methylation about prognosis has been shown previously in CRC by Ward and colleagues, for a "CIMP-like" phenotype (43). The mechanisms underlying this paradox are still not clear. An explanation could be the increased lymphocytic infiltrate that is observed in MSI CRCs (44) or the extent of instability making MSI tumor cells less fit to metastasize $(45,46)$. The prognostic effect of CHFR in MSS stage II CRCs is surprising, as we previously reported a strong association between CHFR promoter CpG island methylation, MSI, and MLH1 promoter methylation in CRC (47). However, because a 
significant subset of MSS CRCs also has CHFR promoter methylation, this could be of clinical relevance.

The biologic role of CHFR also points to a role in cancer progression and metastasis. CHFR is a tumor suppressor gene which is inactivated by promoter CpG island methylation in a variety of solid tumors (47-51). It encodes an ubiquitin ligase that regulates both entry into metaphase and chromosome segregation later in mitosis to maintain genomic stability $(52,53)$. CHFR inactivation has been hypothesized to be associated with CIN, although conflicting data have been reported $(54,55)$. Although both CHFR and MLH1 contribute to genomic integrity, they function through different mechanisms. CHFR deficiency triggers mild CIN and MLH1 deficiency leading to MSI (56). Recent data from Oh and colleagues 2009 (57) indicate that, in vitro, CHFR binds and downregulates HDAC1 thereby downregulating cyclin-dependent kinase inhibitor 1 and the metastasis suppressors, KAI1 and Cadherin-1. This eventually results in cell-cycle arrest and a less invasive phenotype (58). In addition to a potential role for CHFR as prognostic biomarker, CHFR promoter methylation has been proposed as biomarker for response to microtubule inhibitor taxanes in endometrial (59), cervical (59), oral (60), and gastric cancer (61). Although taxanes are not implemented in CRC treatment because they failed to demonstrate a significant clinical benefit in phase II trials (62), CRCs with CHFR promoter methylation might benefit from taxanes.

In summary, although our study failed to demonstrate a consistent prognostic effect of CIMP, we identified promoter CpG island methylation of CHFR as a prognostic biomarker in stage II, MSS, BRAFWT CRCs in two independent populations.

These data indicate that the evaluation of novel CRC biomarkers requires subgroup analysis reflecting the under-

\section{References}

1. Hanahan D, Weinberg RA. The hallmarks of cancer. Cell 2000;100: 57-70.

2. Schuebel KE, Chen W, Cope L, Glockner SC, Suzuki H, Yi JM, et al. Comparing the DNA hypermethylome with gene mutations in human colorectal cancer. PLoS Genet 2007;3:1709-23.

3. Sjoblom T, Jones S, Wood LD, Parsons DW, Lin J, Barber TD, et al. The consensus coding sequences of human breast and colorectal cancers. Science 2006;314:268-74

4. Wood LD, Parsons DW, Jones S, Lin J, Sjoblom T, Leary RJ, et al. The genomic landscapes of human breast and colorectal cancers. Science 2007;318:1108-13.

5. van Engeland M, Derks S, Smits KM, Meijer GA, Herman JG. Colorectal cancer epigenetics: complex simplicity. J Clin Oncol 2011;29:1382-91.

6. Ogino S, Cantor M, Kawasaki T, Brahmandam M, Kirkner GJ, Weisenberger DJ, et al. CpG island methylator phenotype (CIMP) of colorectal cancer is best characterised by quantitative DNA methylation analysis and prospective cohort studies. Gut 2006;55:1000-6.

7. Ogino S, Kawasaki T, Kirkner GJ, Kraft P, Loda M, Fuchs CS. Evaluation of markers for $\mathrm{CpG}$ island methylator phenotype (CIMP) in colorectal cancer by a large population-based sample. J Mol Diagnostics 2007;9:305-14.

8. Samowitz WS, Albertsen H, Herrick J, Levin TR, Sweeney C, Murtaugh MA, et al. Evaluation of a large, population-based sample supports a lying biology and warrant large-scale validation and clinical trials designed to evaluate the value of CHFR promoter CpG island methylation as a prognostic marker in stage II, microsatellite stable, BRAF WT CRC.

\section{Disclosure of Potential Conflicts of Interest}

L. Van Neste is employed as scientific director in MDxHealth. M. van Engeland has commercial research grant from MDxHealth. No potential conflicts of interest were disclosed by the other authors.

\section{Authors' Contributions}

Conception and design: A.H.G. Cleven, S. Derks, L. Van Neste, M.P. Weijenberg, A.P. de Bruïne, M. van Engeland Development of methodology: A.H.G. Cleven, A.P. de Bruïne, M. van Engeland

Acquisition of data (provided animals, acquired and managed patients, provided facilities, etc.): A.H.G. Cleven, B. Tournier, C. Chapusot, M.P. Weijenberg, A.P. de Bruïne

Analysis and interpretation of data (e.g., statistical analysis, biostatistics, computational analysis): A.H.G. Cleven, K.M. Smits, L. Van Neste, V. Jooste, M.P. Weijenberg, A.P. de Bruïne, M. van Engeland

Writing, review, and or revision of the manuscript: A.H.G. Cleven, S. Derks, M.X.G. Draht, K.M. Smits, V. Melotte, L. Van Neste, M.P. Weijenberg, J.G. Herman, A.P. de Bruïne, M. van Engeland

Administrative, technical, or material support (i.e., reporting or organizing data, constructing databases): A.H.G. Cleven, V. Jooste

Study supervision: A.H.G. Cleven, M.P. Weijenberg, A.P. de Bruïne, M. van Engeland

\section{Acknowledgments}

The authors thank Angela Spiertz for excellent technical assistance.

\section{Grant Support}

This work was performed within the framework of CTMM, the Center for Translational Molecular Medicine, project DeCoDe (grant 03O-101).

The costs of publication of this article were defrayed in part by the payment of page charges. This article must therefore be hereby marked advertisement in accordance with 18 U.S.C. Section 1734 solely to indicate this fact.

Received January 7, 2013; revised March 28, 2014; accepted March 28, 2014; published online June 13, 2014.
$\mathrm{CpG}$ island methylator phenotype in colon cancer. Gastroenterology 2005;129:837-45.

9. Shen L, Toyota M, Kondo Y, Lin E, Zhang L, Guo Y, et al.Integrated genetic and epigenetic analysis identifies three different subclasses of colon cancer. Proc Natl Acad Sci U S A 2007;104:18654-9.

10. Toyota M, Ahuja N, Ohe-Toyota M, Herman JG, Baylin SB, Issa JP. $\mathrm{CpG}$ island methylator phenotype in colorectal cancer. Proc Natl Acad Sci U S A 1999;96:8681-6.

11. Weisenberger DJ, Siegmund KD, Campan M, Young J, Long TI, Faasse $\mathrm{MA}$, et al. CpG island methylator phenotype underlies sporadic microsatellite instability and is tightly associated with BRAF mutation in colorectal cancer. Nature Genet 2006;38:787-93.

12. Hughes LA, Khalid-de Bakker CA, Smits KM, van den Brandt PA Jonkers D, Ahuja N, et al. The CpG island methylator phenotype in colorectal cancer: progress and problems. Biochim Biophys Acta 2012;1825:77-85.

13. Ogino S, Meyerhardt JA, Kawasaki T, Clark JW, Ryan DP, Kulke MH, et al. CpG island methylation, response to combination chemotherapy, and patient survival in advanced microsatellite stable colorectal carcinoma. Virchows Arch 2007;450:529-37.

14. Samowitz WS, Sweeney C, Herrick J, Albertsen H, Levin TR, Murtaugh MA, et al. Poor survival associated with the BRAF V600E mutation in microsatellite-stable colon cancers. Cancer Res 2005;65:6063-9. 
15. Shen L, Catalano PJ, Benson ABIII, O'Dwyer P, Hamilton SR, Issa JP. Association between DNA methylation and shortened survival in patients with advanced colorectal cancer treated with 5-fluorouracil based chemotherapy. Clin Cancer Res 2007;13:6093-8.

16. Ogino S, Nosho K, Kirkner GJ, Kawasaki T, Meyerhardt JA, Loda M, et al. CpG island methylator phenotype, microsatellite instability, BRAF mutation and clinical outcome in colon cancer. Gut 2009; 58:90-6.

17. Hughes LA, Melotte V, de Schrijver J, de Maat M, Smit VT, Bovee JV, et al. The $\mathrm{CpG}$ island methylator phenotype: what's in a name? Cancer Res 2013;73:5858-68

18. Wiggers T, Jeekel J, Arends JW, Brinkhorst AP, Kluck HM, Luyk Cl, et al. No-touch isolation technique in colon cancer: a controlled prospective trial. Br J Surg 1988;75:409-15.

19. Wiggers $T$, Arends JW, Volovics A. Regression analysis of prognostic factors in colorectal cancer after curative resections. Dis Colon Rectum 1988;31:33-41.

20. Van den Brandt PA, Schouten LJ, Goldbohm RA, Dorant E, Hunen PM. Development of a record linkage protocol for use in the Dutch Cancer Registry for Epidemiological Research. Int J Epidemiol 1990;19:553-8.

21. de Vogel S, Wouters KA, Gottschalk RW, van Schooten FJ, de Goeij $A F$, de Bruine AP, et al. Genetic variants of methyl metabolizing enzymes and epigenetic regulators: associations with promoter CpG island hypermethylation in colorectal cancer. Cancer Epidemiol Biomark Prev 2009;18:3086-96.

22. Choi JS, Kim KH, Jeon YK, Kim SH, Jang SG, Ku JL, et al. Promoter hypermethylation of the ADAM23 gene in colorectal cancer cell lines and cancer tissues. Int J Cancer J Int du Cancer 2009;124:1258-62.

23. Wanajo A, Sasaki A, Nagasaki H, Shimada S, Otsubo T, Owaki S, et al. Methylation of the calcium channel-related gene, CACNA2D3, is frequent and a poor prognostic factor in gastric cancer. Gastroenterology 2008;135:580-90.

24. Herman JG, Graff JR, Myohanen S, Nelkin BD, Baylin SB. Methylationspecific PCR: a novel PCR assay for methylation status of $\mathrm{CpG}$ islands. Proc Natl Acad Sci U S A 1996;93:9821-6.

25. Derks S, Lentjes MH, Hellebrekers DM, de Bruine AP, Herman JG, van Engeland M. Methylation-specific PCR unraveled. Cell Oncol 2004; 26:291-9.

26. Suraweera N, Duval A, Reperant M, Vaury C, Furlan D, Leroy K, et al. Evaluation of tumor microsatellite instability using five quasimonomorphic mononucleotide repeats and pentaplex PCR. Gastroenterology 2002;123:1804-11.

27. Luchtenborg M, Weijenberg MP, Wark PA, Saritas AM, Roemen GM, van Muijen GN, et al. Mutations in APC, CTNNB1 and K-ras genes and expression of $\mathrm{hMLH} 1$ in sporadic colorectal carcinomas from the Netherlands Cohort Study. BMC Cancer 2005;5:160.

28. Sieben NL, Roemen GM, Oosting J, Fleuren GJ, van Engeland M, Prat J. Clonal analysis favours a monoclonal origin for serous borderline tumours with peritoneal implants. J Pathol 2006;210:405-11.

29. Carlis J, Bruso K. How many clusters to report: a recursive heuristic. Conference proceedings: Annual International Conference of the IEEE Engineering in Medicine and Biology Society; 2010:1069-72.

30. Kaushal D, Naeve CW. Loading and preparing data for analysis in spotfire. Curr Protoc Bioinformatics 2004;Chapter 7:Unit 78.

31. Worthley DL, Whitehall VL, Spring KJ, Leggett BA. Colorectal carcinogenesis: road maps to cancer. World J Gastroenterol 2007;13: 3784-91.

32. Kawasaki T, Ohnishi M, Nosho K, Suemoto Y, Kirkner GJ, Meyerhardt $\mathrm{JA}$, et al. CpG island methylator phenotype-low (CIMP-low) colorectal cancer shows not only few methylated CIMP-high-specific CpG islands, but also low-level methylation at individual loci. Mod Pathol 2008;21:245-55

33. Lee S, Cho NY, Choi M, Yoo EJ, Kim JH, Kang GH. Clinicopathological features of $\mathrm{CpG}$ island methylator phenotype-positive colorectal cancer and its adverse prognosis in relation to KRAS/BRAF mutation. Pathol Int 2008;58:104-13.

34. Derks S, Postma C, Carvalho B, van den Bosch SM, Moerkerk PT, Herman JG, et al. Integrated analysis of chromosomal, microsatellite and epigenetic instability in colorectal cancer identifies specific associations between promoter methylation of pivotal tumour suppressor and DNA repair genes and specific chromosomal alterations. Carcinogenesis 2008;29:434-9.

35. Ogino S, Kawasaki T, Kirkner GJ, Loda M, Fuchs CS. CpG island methylator phenotype-low (CIMP-low) in colorectal cancer: possible associations with male sex and KRAS mutations. J Mol diagnostics;8:582-8.

36. Hinoue $T$, Weisenberger DJ, Lange $C P$, Shen $H$, Byun HM, Van Den Berg D, et al. Genome-scale analysis of aberrant DNA methylation in colorectal cancer. Genome Res 2012;22:271-82.

37. Popat S, Hubner R, Houlston RS. Systematic review of microsatellite instability and colorectal cancer prognosis. J Clin Oncol 2005;23: 609-18.

38. Zlobec I, Kovac M, Erzberger P, Molinari F, Bihl MP, Rufle A, et al. Combined analysis of specific KRAS mutation, BRAF and microsatellite instability identifies prognostic subgroups of sporadic and hereditary colorectal cancer. Int J Cancer J int du Cancer 2010; 127:2569-75

39. Tanaka M, Chang P, Li Y, Li D, Overman M, Maru DM, et al. Association of CHFR promoter methylation with disease recurrence in locally advanced colon cancer. Clin Cancer Res 2011;17:4531-40.

40. Barault L, Charon-Barra C, Jooste V, de la Vega MF, Martin L, Roignot $P$, et al. Hypermethylator phenotype in sporadic colon cancer: study on a population-based series of 582 cases. Cancer Res 2008;68:8541-6.

41. Draht MXG, Smits KM, Tournier B, Jooste V, Chapusot C, Carvalho B, et al. Promoter $\mathrm{CpG}$ island methylation of RET predicts poor prognosis in stage II colorectal cancer patients. Mol Oncol. 2014 Feb 2. pii: S1574-7891(14)00025-8.

42. van Vlodrop IJ, Niessen HE, Derks S, Baldewijns MM, van Criekinge W, Herman JG, et al. Analysis of promoter $\mathrm{CpG}$ island hypermethylation in cancer: location, location, location! Clin Cancer Res 2011;17:4225-31.

43. Ward RL, Cheong K, Ku SL, Meagher A, O'Connor T, Hawkins NJ. Adverse prognostic effect of methylation in colorectal cancer is reversed by microsatellite instability. J Clin Oncol 2003;21:3729-36.

44. Quinn E, Hawkins N, Yip YL, Suter C, Ward R. CD103+ intraepithelial lymphocytes-a unique population in microsatellite unstable sporadic colorectal cancer. Eur J Cancer 2003;39:469-75.

45. Lamlum H, llyas M, Rowan A, Clark S, Johnson V, Bell J, et al. The type of somatic mutation at APC in familial adenomatous polyposis is determined by the site of the germline mutation: a new facet to Knudson's 'two-hit' hypothesis. Nat Med 1999;5:1071-5.

46. Tomlinson I, Bodmer W. Selection, the mutation rate and cancer: ensuring that the tail does not wag the dog. Nat Med 1999;5:11-2.

47. Brandes JC, van Engeland M, Wouters KA, Weijenberg MP, Herman JG. CHFR promoter hypermethylation in colon cancer correlates with the microsatellite instability phenotype. Carcinogenesis 2005;26: 1152-6.

48. Mizuno K, Osada H, Konishi H, Tatematsu Y, Yatabe Y, Mitsudomi T, et al. Aberrant hypermethylation of the CHFR prophase checkpoint gene in human lung cancers. Oncogene 2002;21:2328-33.

49. Shibata $Y$, Haruki N, Kuwabara $Y$, Ishiguro $H$, Shinoda N, Sato A, et al Chfr expression is downregulated by $\mathrm{CpG}$ island hypermethylation in esophageal cancer. Carcinogenesis 2002;23:1695-9.

50. Corn PG, Summers MK, Fogt F, Virmani AK, Gazdar AF, Halazonetis $T D$, et al. Frequent hypermethylation of the $5^{\prime} \mathrm{CpG}$ island of the mitotic stress checkpoint gene Chfr in colorectal and non-small cell lung cancer. Carcinogenesis 2003;24:47-51.

51. Satoh A, Toyota M, Itoh F, Sasaki Y, Suzuki H, Ogi K, et al. Epigenetic inactivation of CHFR and sensitivity to microtubule inhibitors in gastric cancer. Cancer Res 2003;63:8606-13.

52. Kang D, Chen J, Wong J, Fang G. The checkpoint protein Chfr is a ligase that ubiquitinates Plk1 and inhibits $\mathrm{Cdc} 2$ at the $\mathrm{G} 2$ to $\mathrm{M}$ transition. J Cell Biol 2002;156:249-59.

53. Scolnick DM, Halazonetis TD. Chfr defines a mitotic stress checkpoint that delays entry into metaphase. Nature 2000;406:430-5

54. Maddika S, Sy SM, Chen J. Functional interaction between Chfr and Kif22 controls genomic stability. J Biol Chem 2009;284: 12998-3003

55. Bertholon J, Wang Q, Falette N, Verny C, Auclair J, Chassot C, et al. Chfr inactivation is not associated to chromosomal instability in colon cancers. Oncogene 2003;22:8956-60. 
56. Fu Z, Regan K, Zhang L, Muders MH, Thibodeau SN, French A, et al. Deficiencies in Chfr and Mlh1 synergistically enhance tumor susceptibility in mice. J Clin Invest 2009;119:2714-24.

57. Oh YM, Kwon YE, Kim JM, Bae SJ, Lee BK, Yoo SJ, et al. Chfr is linked to tumour metastasis through the downregulation of HDAC1. Nat Cell Biol 2009;11:295-302.

58. Derks S, Cleven AH, Melotte V, Smits KM, Brandes JC, Azad N, et al. Emerging evidence for CHFR as a cancer biomarker: from tumor biology to precision medicine. Cancer Metastasis Rev 2014;33:16171.

59. Banno K, Yanokura M, Kawaguchi M, Kuwabara Y, Akiyoshi J, Kobayashi Y, et al. Epigenetic inactivation of the CHFR gene in cervical cancer contributes to sensitivity to taxanes. Int $\mathrm{J}$ Oncol 2007;31: 713-20.

60. Ogi K, Toyota M, Mita H, Satoh A, Kashima L, Sasaki Y, et al. Smal interfering RNA-induced CHFR silencing sensitizes oral squamous cell cancer cells to microtubule inhibitors. Cancer Biol Ther 2005;4: 773-80.

61. Koga $Y$, Kitajima $Y$, Miyoshi A, Sato K, Sato S, Miyazaki K. The significance of aberrant CHFR methylation for clinical response to microtubule inhibitors in gastric cancer. J Gastroenterol 2006;41: 133-9.

62. Swanton C, Tomlinson I, Downward J. Chromosomal instability, colorectal cancer and taxane resistance. Cell Cycle 2006;5:818-23. 


\section{Clinical Cancer Research}

\section{CHFR Promoter Methylation Indicates Poor Prognosis in Stage II Microsatellite Stable Colorectal Cancer}

Arjen H.G. Cleven, Sarah Derks, Muriel X.G. Draht, et al.

Clin Cancer Res 2014;20:3261-3271.

\section{Updated version Access the most recent version of this article at:}

$\mathrm{http}: / /$ clincancerres.aacrjournals.org/content/20/12/3261

Supplementary Access the most recent supplemental material at:

Material http://clincancerres.aacrjournals.org/content/suppl/2015/07/17/20.12.3261.DC1

Cited articles This article cites 57 articles, 21 of which you can access for free at:

http://clincancerres.aacrjournals.org/content/20/12/3261.full\#ref-list-1

E-mail alerts Sign up to receive free email-alerts related to this article or journal.

Reprints and To order reprints of this article or to subscribe to the journal, contact the AACR Publications Department at Subscriptions pubs@aacr.org.

Permissions To request permission to re-use all or part of this article, use this link http://clincancerres.aacrjournals.org/content/20/12/3261.

Click on "Request Permissions" which will take you to the Copyright Clearance Center's (CCC)

Rightslink site. 